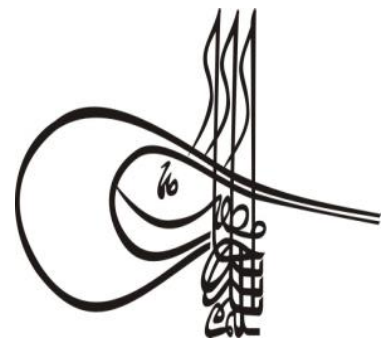

\begin{abstract}
(n)
\end{abstract}
Received/Geliș: 25.11.2019

earch Article / Arasturma Makalesi

Article Info/Makale Bilgisi

Skopje/MACEDONIA-Ankara/TURKEY

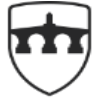

INTERNATIONAL BALKAN UNIVERSITY

EXCELLENCE FOR THE FUTURE IBU.EDU.MK

\Accepted/Kabul: 20.12.2019

Gonort Dates/Rapor Tarihleri: Referee 1 (01.12.2019)-Referee 2 (03.12.2019)

This article was checked by iThenticate.

\title{
BİR MASAL KARŞILAŞTIRMASI: RAPUNZEL İLE MAHBUB-I DÍLBER*
}

\author{
Sunay AKKAYA**
}

\begin{abstract}
öz
Masallar, mitler gibi insanlığın ortak deneyimlerinin bir ürünüdür. Bütün insanlığın ortak yaşam tarzının, yani insan olmanın gereğini yerine getirmenin izlerini süreceğimiz soyut yasaları, somut bir dille anlatır. Böylece unutulmaya yüz tutmuş değerlere yeniden bilinç verir. Dünya üzerinde yaşayan farklı toplulukların masalları karşılaştırıldığında bir toplumda var olan bir kültürel kodun diğerinde de var olabileceğini ispatlar. Bu durum günümüz dünyasinda kültür endüstrisi alanında her topluluğun kendisine yer bulabileceğinin ve bunun yanında yerel kültürlerin, tek tipleşme karşısında yok olmasını engellenebileceğinin çözümünü sunar. Kültür endüstrisi alanına aktarılan her yerel masalın yeniden canlanması, Batı'nın kültürel kodlarıyla büyüyen nesillerin kendi kültürel kimliğnin sınırlarını çizmesinin ipuçlarını verir. Anadolu masallarından Nardaniye Hanım masalının Batı varyantı Pamuk Prenses, Nohut Oğlan'in Batı varyantı Parmak Çocuk, Küllü Fatma'nın Batı varyantı Sindirella olarak halkbilimciler tarafından tespit edilmiştir. Bu çalışmada ise Adıyaman kentinde derlenmiş "Mahbub-1 Dilber" (Sabır Taşı) masalının Batı varyantında Grimm Kardeşlerin derlediği "Rapunzel'in karşılı̆gı olduğu tespit edilmiştir. Çalışmada Rapunzel ile Mahbub-1 Dilber masalı karşlaştırmalı edebiyat yöntemi ile ele alınmış, bunların benzer ve farklı kültürel kodlarının ortaya konması amaçlanmıştır. Ayrıca masalın evrensel boyutundan hareketle soyut yasalarının hangi kültür olursa olsun değissmediği görülmüștür. Her iki masalın benzer ve farklı yönlerinin olduğu görülmüştür. Kültür endüstrisi alanında ana ve yan sektörlerde bu türden Anadolu masallarının birer ürüne
\end{abstract}

\footnotetext{
* Bu çalışma, 27-29 Eylül 2018 tarihlerinde Üsküp'te / Makedonya'da gerçekleştrilen Uluslararası Türk Kültürü ve Dili Sempozyumu'nda sunulan "Bir Masal Karşılaştırması: Rapunzel ile Mahbub-1 Dilber" isimli bildirinin genişletilmiş halidir.
} 
dönüştürülerek yeni nesillere kültürel kod aktarımının yapılabileceği sonucuna ulaş1lmıştır.

Anahtar Kelimeler: Rapunzel, Mahbub-1 Dilber, Masal, Karşılaştırmalı Yöntem, Kültür Endüstrisi.

\title{
A FOLK TALE COMPARISON: RAPUNZEL AND MAHBUB-I DILBER
}

\begin{abstract}
Folk tales, like myths, are the product of the common experiences of humanity. They describe the abstract laws, which bear the traces of the common life style of all humanity, that is, an essential part of being human, in a concrete language. Thus, they revive the values that have almost sunk into oblivion. When the folk tales of various world societies are compared, they prove that a cultural code that exists in one society can exist in another. This suggests that every community can find a place for itself in the global cultural industry today and that preventing the disappearance of local cultures in the face of uniformization is indeed possible. The revival of every local folk tale transferred to the field of cultural industry helps generations that grow with the cultural codes of the West to draw the boundaries of their own cultural identity. Regarding Anatolian folk tales, that the Western version of "Nardaniye Hanım" is "Snow White," the Western version of "Nohut Oğlan (Chickpea Boy)" is "Finger Child", and the Western version of "Küllü Fatma" is "Cinderella" has been confirmed by folklorists. Collected in the city of Adiyaman, the "Mahbub-1 Dilber" (as patient as Job) folk tale has been found out to be a counterpart of "Rapunzel", which was compiled by Grimm Brothers. In the present study, Rapunzel and Mahbub-1 Dilber tales were analyzed comparatively, aiming to reveal the similar and different cultural codes they have. Moreover, considering the universal dimension of the folk tale, it was found that the abstract laws of the tale remain the same regardless of the local culture. Both tales were found to have similar and different aspects. It was concluded that by converting such Anatolian tales into products in the main and subsectors of the cultural industry, they can be transferred to new generations.
\end{abstract}

\section{STRUCTURED ABSTRACT}

Folk tale studies are the most productive part of the folklore (ethnology) history. The subject of folk tale led to the emergence of many theoretical movements in the early studies of folklore. Today, however, this type of storytelling is increasing in importance because of its transformation into a stage art, making use of tales in the film industry, and the emergence of fairy tale therapy as a therapy method in psychology. Tales of the western culture are used in these areas. Particularly at the global scale, the western-based tales are preferred by the cultural industry, leading to cultural uniformity and disappearance of local cultures. This is witnessed in every aspect of our daily lives. Tales actually have a function to shape our lives through the

Turkish Studies - Language and Literature

Volume 14 Issue 4, 2019 
main and sub-sectors of the cultural industry. For example, the "Rapunzel" tale is adopted not only by the film industry, but also a wide range of activities and items including birthdays, dolls, jigsaws, costumes, and hair designs. Folk tales continue to be demanded as a cultural-economic product due to their transformative effect on the human life. However, the young Turkish generations are observed not to be aware of the existence of Turkish folk tales except those made into animation. Therefore, comparative folk tale studies play a key role in ensuring that local tales are not forgotten and revived against the globalized tales. To make sure that the Anatolian tales are embraced by the young Turkish generations and cultural codes are successfully transferred to them through folk tales, carrying out comparative fairy tale studies seems crucial.

"Rapunzel" and "Mahbub-1 Dilber" tales are regarded as ecotypes and this study does not aim to prove that one of the tales is better than the other, as the historical geographical Finnish theory does. The main purpose is to decipher the abstract laws of narratives in terms of reality by comparing tales and to better understand the functions of tales that are transformed into an object of consumption in today's world in human life. Thus, the transfer of Anatolian tales to the field of cultural industry can gain meaning.

In the comparison of fairy tales, no single theoretical method was used. Instead, the accumulation of comparative academic studies in general and the theoretical experience and theoretical systematics of folklore discipline in particular were utilized. In this study, two folk tales were examined by using comparative method. One of the tales studied is Rapunzel, a folk tale in the European culture popularized in the world through the means of communication, and the other is a newly-identified folk tale compiled from the South East of Turkey (Adiyaman). The folk tales were compared in terms of form features, time, place, motif and individuals. The reason for the comparison of these two folk tales is the length of the hair of Mahbub-1 Dilber and Rapunzel compiled from Adiyaman, the fact that they are the only girls of the family, that the starting place of the test starts on a single window axis and that there are similar motifs in both folk tales. The compilation dates of the tales compared differ. The Grimm Tales were compiled in 1812-1822 and the Adryaman Tales in 2014-2015. Although it is an appropriate approach to consider this time difference in the comparative analysis of fairy tales, the reality dimension that transcends all times and subjects is not affected much by this time difference. Rapunzel and Mahbub-1 Dilber, W. Eberhard and P. N. Boratav (1953) brought together more than one folk tale type according to the folk tale types in the Turkish fairy tale catalog, namely, the destiny of people is predetermined and will not change (Type 20), and the poor girl marries the rich man (Type 16) (Erhard-Boratav, 1953). The main theme of both folk tales was determined to be an attempt to defeat destiny. These are the visible part of the iceberg on the surface of the tale. When deeper readings are made, it can be seen that unconscious experiences turn into principles in fairy tales. The principle is the transformation of experience into action. In other words, experiences and actions are transferred to folk tales through behaviors. The term "abstract folk tale type" is used to express this structure. Therefore, both folk tales were found to depend on an abstract type of

\section{Turkish Studies - Language and Literature}

Volume 14 Issue 4, 2019 
folk tale: Life is based on price and money. It was found that this abstract main law includes multiple interrelated sub-laws, as well. Depending on this abstract law, the "every deferred price grows incrementally" sub-law was revealed by comparing the two folk tales. Thus, it was seen that the events progressed and ended not accidentally but in a step-by-step fashion through causal relationships. The folk tales were compared by their starting form, the ending form, the verse pieces, episodes that are connected to the verse pieces, time, people, space, and motifs. Thus, by comparing Mahbub-1 Dilber and Rapunzel tales belonging to two different cultures, it was found that both tales have similar and different motifs. It was found that the main motifs created similarities in these folk tales and the differences were caused by intermediate motifs. It was further found that there were more similar aspects between the two tales than differences. It was concluded that the cultural code difference between folk tales stems from the fact that each folk tale is a geographical ecotype. This comparative study of local folk tale types may contribute to the inclusion of Turkish tales in the field of cultural industry.

Keywords: Rapunzel, Mahbub-1 Dilber, Folk tale, Comparative Method, Culture Industry

\section{Giriş}

Masal çalışmaları halk bilimi tarihinin en verimli ürünlerini oluşturur. Masal konusu halk biliminin ilk dönem çalışmalarında kuramsal ve teorik birçok akımın doğmasına öncülük etmiştir. Günümüzde ise masal anlatmanın bir sahne sanatına dönüşmesi, film endüstrisinde masallardan yararlanılması, psikolojide bir terapi yöntemi olarak masal terapisinin gündeme gelmesi gibi durumlardan ötürü gittikçe önemini arttıran bu türdür. Söz konusu bu alanlarda batı kültürünün masallarından yararlanılmaktadır. Özellikle kültür endüstrisinin küresel boyutunda batı merkezli masalların tercih edilmesi kültürel tek tipleşmeyi beraberinde getirirken yerel kültürlerin unutulmasına neden olmaktadır. Bu durum günlük yaşamımızın her alanında görülmektedir. Masallar aslında kültür endüstrisinin ana ve yan sektörleri üzerinden yaşamımızı şekillendirici bir işleve sahiptir. Örneğin "Rapunzel" masalı sadece film endüstrisi değil, yeni doğan bebeğin ilk doğduğu günden doğum günlerine, oyuncak bebeğinden yapboza, kostümden saç tasarımına kadar geniş bir yelpazeyi kaplamaktadır. Masalların insan yaşamını dönüştürücü etki nedeniyle kültür endüstrisi alanlarına kültürel ekonomik bir ürün olarak rağbet görmeye devam etmektedir. Dolayısıyla yeni nesillerin Türk masallarının varlığından animasyona dönüştürülmüş olanlar dışında, haberdar olmadıkları gözlemlenmektedir. Bu nedenle küreselleşen masalların karşısında yerel masalların unutulmaması ve yeniden canlandırılması için karşılaştırılmalı masal çalışmalarını önemli hale getirmektedir.

Halkbilimi tarihinde ilk dönem yapılan karşılaştırmalı çalışmalar bir türün ilk nerede ortaya çıktığını ortaya koymaya yöneliktir. Bu durum halk biliminin üniter yapıdaki devletleri kurma aşamasında ideolojik olarak bir işlevi üstlenmesinin bir sonucudur. Çünkü bir türün ilk nerede ortaya çıktığının tespiti anlatı türünün ait olduğu toplumu dünyada güçlü bir pozisyona yükseltmesiyle eş değerdir. Dolayısıyla 1960'larda ulusların kültür politikalarını belirleme sürecinde batı kültürünün dünyaya kitle iletişim araçları üzerinden yayılarak yerel kültürleri yok ettiği gündemde olan ve günümüzde de olmaya devam eden bir konudur. Fakat toplumların coğrafi ve kültürel olarak yeniden kurgulandığı günümüz dünyasında karşılaştırmalı yöntemle, farklılıkları kültürel kimliği tanımlamada ortaklıkları ise göçlerle bir araya gelen toplumların hoşgörü içinde yaşaması kapsamında değerlendirilmektedir. Ama halkbilimsel üretimler daha çok sömürge sonrası 
dönemde hammadde kaynaklarının tükendiği bir ortamda insanlığın ekonomik kalkınmasının önemli bir parçası olarak görülmektedir. Özellikle kültür endüstrisi ve buna bağlı olarak kültür ekonomisi alanında halk anlatılarının önemli bir işlevi vardır. Bu bağlamda kültür endüstrisi alanında halk anlatılarının yoğun bir şekilde kullanıldığı gözlenmektedir. Örneğin bir masalın çizgi animasyonu, masal kitapları, masal kahramanlarının kullandıkları nesneler, kıyafetler, duvar kağıtları vb daha birçok örneklendirilebilecek ürün pazarlanmaktadır. Dolayısıyla bir masalın kültürel kodlarının yaygınlaşmasında ve yeni nesillerin daha kreş çağında yaşam stillerinin oluşmasında kitleselleşen masalların etkisinin olduğu çok yakın çevremizde dahi gözlemlenebilir.

4,5 yaşında bir kız çocuğunun gece uyumadan önce "Anne bana bir masal anlat." demesine karşılık olarak annenin "Sana hangi masalı anlatayım?" sorusuna çocuk "Rapunze'i anlat" cevabını verir. Anne, "Onu değil de sana Rapunzel gibi uzun saçları olan Mahbub-1 Dilber’i anlatayım." der. Çocuğun buna istinaden söyledikleri, aslında kültürel-ekonomik sektörlerin çocukların dünyasını ne kadar çevrelediğini ve bu sektörlerde var olamayan masalların günümüz dünyasında kabul görmediğini anlatmaya kâfidir:

“Ama anne Rapunzel'in saçları çok güzel, sarı ve uzun ve bir de masal kitabında gördüm çok güzel prenses elbisesi var. O bir prenses. Şatoda yaşıyor. Çok güzel hem de. Bir de ben Mahbub-1 Dilber'i hiç görmedim ki, tanımıyorum. Onu anlatma. Rapunzel'i anlat."

ADYÜ Yaşayan Kültürel Hazine Müzesine gelen ilkokul 1. sınıf kız öğrencilerinin çoğunluğunun müzenin bahçesine girer girmez "bu pencereden Rapunzel saçlarını mı sarkıtacak, içerde pamuk prenses de var mı, bize Sindirella masalını mı anlatacaksınız?" Ya da masal anlatıcısının "size cadılı bir Anadolu masalı anlatayım", sözüne karşılık çocukların "Aaaa Anadolu masallarında cadı mı varmış?" sorusunu sorması yeni neslin kendi kültürel kodlarından haberdar olmadıklarını gösterir.

Anadolu masallarının yeni nesiller arasında kabul görebilmesi ve kültürel kodların masallar vasıtasıyla yeni nesillere aktarılması kapsamında karşıllaştırmalı masal çalışmalarına eğilmek önemli bir durum olarak ortaya çıkmaktadır. $\mathrm{Bu}$ kapsamda kültür endüstrisi aracıllğıyla yaygınlaşmış olan masalların kültürel kod karşılıkları, Anadolu masallarında masal anlatıcısının "Cadı neye biner?" sorusuna karşılık tespit edilerek kültür endüstrisi alanına kazandırılmalıdır. Kendi kültürel kodlarıyla yetişmeyen nesiller kendi yaşam stillerini de bu anlatılara göre dizayn eder. Çünkü anlatıların insan yaşamını dönüştürücü bir gücü ve etkisi vardır.

\section{Amaç}

Rapunzel ve Mahbub-1 Dilber** masallarının ekotip olarak kabul edildiği bu çalışmada amaç, Tarihi Coğrafi Fin kuramındaki gibi, masallardan birinin diğerinden daha yegâne olduğunu ispatlamak değildir. Asıl amaç masalları karşılaştırarak anlatıların gerçeklik boyutundaki soyut yasalarını deşifre etmek ve günümüz dünyasında bir tüketim nesnesine dönüştürülen masalların aslında insan hayatındaki işlevlerini daha iyi anlayabilmektir. Böylece kültür endüstrisi alanına Anadolu masallarının aktarılması bir anlam kazanabilir. Bu kapsamda, çalışmada sadece bir kuramsal yönteme bağlı kalınmamıştır. Bunun yerine genelde karşılaştırmalı akademik çalışmaların birikimlerinden, özelde ise halkbilimi disiplininin kuramsal deneyimlerinden ve kuramsal sistematiğinden yararlanılmıştır.

\section{Yöntem}

Akademik disiplinlerin birçoğu doğası ve alanı gereği karşılaştırmalıdır (Dundes, çev. Çalış, 2007, 81). Halkbilimi kuramlarının ortaya çıkmasında masalların önemli bir yeri vardır. Halkbilimi alanında da özellikle masalların 19. yüzyılda karşılaştırmalı yöntem olarak bilinen Tarihi-Coğrafi Fin yöntemi kullanılarak sistematik bir düzleme oturtulduğu görülmektedir (Krohn ve Krohn, 2004). Ancak bu yöntem bir masalın ur-formunu yani bir masalın ortaya çıktığı ilk

\section{Turkish Studies - Language and Literature}

Volume 14 Issue 4, 2019 
şeklini bulmaya yönelik olduğundan çokça eleştirilmiş ve bu eleştiriler neticesinde masal incelemelerinin daha uygulanabilir ve sonuçlanabilir bir zeminde incelenmesine öncülük etmiştir. Özellikle İsveçli Carl Wilhelm Von Sydow'un folklorun karşılaştırmalı yöntemine botanik biliminden ödünç aldığı ekotip terimini yerleştirmesi karşılaştırmalı yöntemi uygulanabilir kılmıştır. Bu terim bir bitkinin yerli veya bölgesel tipine verilen isimdir. Bu görüşün temelinde bir masalın veya diğer halk anlatılarının coğrafyalar arası göçü yer alır. Nasıl bir bitki farklı bölgelerdeki farklı iklim ve toprak koşullarına uyum sağlıyorsa halk masalları da aynı şekilde bir bölgeden ülkeden diğerine hareket ettikçe yerel özelliklere uyum sağlar (von Sydow, 2005, 109). Dolayısıyla ekotip, karşılaştırmalı yöntemin mantıksal bir uzantısı olarak görülür.

Çalışmada iki masal karşılaştırmalı yöntem kullanılarak incelenmiştir. İncelenen masallardan birisi Avrupa kültüründe yer alan ve iletişim araçları vasıtasıyla tüm dünyada bilinen bir masal olan Rapunzel, diğeri henüz Güney Doğu Anadolu'dan (Adıyaman'dan) derlenen yeni tespit edilmiş bir masaldır. Masallar şekil özellikleri, zaman, mekân, motif ve şahıs kadrosu kapsamında karşılaştırılmıştır. Bu iki masalın karşılaştırılmasının sebebi Adıyaman'dan derlenen Mahbub-1 Dilber ile Rapunzel'in saçlarının uzunluğu, ailenin tek kız çocuğu olmaları, sınanmanın başlangıç mekânının tek pencere ekseninde başlaması, her iki masal mekânında da kapının olmaması gibi benzer motiflerinin olmasıdır. Karşılaştııılan masalların derlenme tarihleri arasında zaman fark1 bulunmaktadır. Grimm Masalları 1812-1822, Adıyaman Masalları 2014-2015 yıllarında derlenmiştir. Masalların karşılaştırmalı olarak incelenmesinde bu zaman farkının göz önünde bulundurulması uygun bir yaklaşım olsa da tüm zamanları ve konuları aşarak gelen gerçeklik boyutu bu zaman farkından çok fazla etkilenmez. Rus araştırmacılar, masal anlatıcılarının kişisel deneyim ve kişiliklerin anlatılan masal üzerinde önemli bir rolü olduğunu tespit etmişlerdir (Azadowski 2002, Bkz. Ergun, 2014, 103). Bu kapsamda masal araştırmaları tarihinde masallar gerçek dış1, hayal ürünü anlatılar olarak kabul edilmesine rağmen masalların geçmişten günümüze bütün insanlığın kolektif bilinç dışının yani ortak deneyiminin bir ürünü olduğunu ve gerçekleri anlattığını söylemek mümkündür. Buna ek olarak antik ve modern insanların rüyalarındaki anlatım tarzı ile insanlık tarihi başlarında oluşturulmuş olan mitosların ve buna ek olarak masalların anlatım tarz1 da aynıdır (Fromm, 2003, 18-19). Her topluluğun sahip olduğu masal belleği, aslında yeryüzünde var olan fizik, astronomi, tıp alanlarındaki somut yasalar kadar gerçek ve değişmeyen soyut yasaları da deşifre etme imkânı sunar. Çünkü modern çağ insanının zihninde, bilimsellik kaygısından doğan bir yaklaşımın ürünü olarak, felsefi akımların da öncülüğünde, belirsizlik üzerine kurulu bir hayat döngüsünün insan hayatında ve davranışında var olduğu fikri yerleşmiştir. Ancak gerçekte tıpkı somut yasalarda olduğu gibi "yer çekimi yasası"nda düşme reaksiyonuyla karşılaşacağından emin olmak kadar korkan insanın da kalbinin hızla çarpacağı reaksiyonundan şüphe edilemez. $\mathrm{Bu}$ durum aslında soyutta olan korkunun somut bedendeki yansımasıdır. Dolayısıyla soyutta yapılan bir hatanın (örneğin, aza kanaat etmeme), başkasının sahip olduğu şeyden acı duyma tepkilerinin gerçek hayatta anlık olarak değil de toplamda bir reaksiyonunun olduğunu zamanlar arası bir iletişim ağı olan masallar aracıllğıyla öğrenilir. Bu nedenle masallar hep aynı olay döngüsüne sahiptir. Çünkü somut yasalar değişmediği gibi bu hayatta soyut yasalar da değişmez. Sadece masalların şahıs kadrosu motifleri, isimleri değişir ama gerçekliği hiç değişmez. Böylece topluluğun bilincini sürekli açık tutma işlevini de yerine getirir. Özetle masallar, insanlığın ortak deneyiminin, gerçekliğinin bir ürünü olarak soyutta deneyimlediği hayatın yasalarını anlatılar şeklinde sembol dilinden de yararlanarak ete kemiğe büründürüp somutlaştırır. $\mathrm{Bu}$ yönüyle masallar deneyim transferi yapan metinler olarak hayatı öngörme konforunu yaşatan gizli bir dünyanın kapılarını aralar.

Rapunzel ve Mahbub-1 Dilber, W. Eberhard ve P. N. Boratav (1953) Türk masal kataloğundaki masal tiplerine göre birden fazla masal tipini bir araya getirmiş̧ir. İnsanların kaderinin önceden yazıldığı ve değişmeyeceği (20. Tip), fakir kızın zengin erkekle evlenmesi (16. Tip) (Erhard- Boratav, 1953). Her iki masalın ana teması ise alın yazısını yenme çabasıdır. Bunlar 
masalın yüzeyindeki buz dağının görünen kısmıdır. Daha derin okumalar yapıldığında aslında bilinç dışındaki deneyimlerin masallarda birer prensibe dönüştüğü görülür. Prensip deneyimin eyleme dönüştürülmesidir. Yani deneyimler, eylemler bir başka değişle davranışlar aracılığıyla masallara aktarılırlar. Bu yapıyı karşılamak üzere soyut masal tipi terimini kullanmak yerinde olacaktır. Dolayısıyla her iki masal özünde bir soyut masal tipine bağlıdır: Hayat, bedel ve karşılığı üzerine kuruludur. $\mathrm{Bu}$ ana yasa, altında birden fazla ve birbiriyle ilişkili alt yasaları da kapsar. Böylece olayların tesadüfen değil birbiriyle ilintili sebep- sonuç ilişkisi kapsamında basamak basamak ilerlediği ve nihayete erdiği görülür.

\section{Bulgular}

\section{Masalın Soyut Yasaları}

\section{Hayat, bedel ve karşıllğı üzerine kuruludur}

Günümüz insanı masal anlatmayı nostaljik bir durum olarak algılar. "Bana masal anlatma" söylemiyle de masal anlatmayı aslında boş laf konuşmak gibi negatif bir anlamda aktarır. Fakat geçmiş dönemlerde masalların işlevsel olarak diğer halk anlatıları gibi toplumu eğitme işlevi vardı. Geçmiş toplumlarda masal anlatıcılarının kimliğine bakıldığında önemli bir görevi icra ettikleri görülür:

"Masal anlatıcılarının ilk atasının, tıpkı ilk şaman ve ilk yönetici gibi yaratılışın başında Tanrı tarafından yer altına gönderilen Erlik tarafından eğitildiğine inanılmaktadır. Bu sayede Erlik/Şeytan hakkında 'gerçek'leri öğrenen ilk anlatıcılar, ondan korunmayı ve masal anlatarak içinde bulundukları toplumları korumayı hedeflemişlerdir.” (Ergun, 2014, 33).

Günümüz toplumlarının yaptığı masal incelemelerinde masalların işlevselliği ve hayatın soyut yasalarını deşifre eden metinler olduğu göz ardı edilmektedir. Bu bağlamda masal incelemelerinde yapılan motif incelemeleri, buz dağının görünen yüzünü anlatmaktan ibarettir. Çünkü bir toplum sahip olduğu kolektif bilinç dışını yani ortak deneyimlerini kaybettikçe daha somut bir bakış açısı kazanır. Fakat Türk ortak deneyim belleğini/kolektif bilinç dışını batı toplumlarının kültürel kodlarıyla içeriklendirmektedir. İncelenen iki masalda geçen pencere motifi masal çalışmalarında mağara, ağaç kovuğu mitolojik motifleriyle ilintili bir biçimde genç kızlıktan kadın olmaya geçiş işleviyle okunmuştur. Fakat sadece bu işlevi göz önünde bulundurulduğunda Rapunzel'in aşeren annesi ve pencereyi nasıl değerlendirmeliyiz? Bu konu hakkında daha detay ve derin bir okumaya ihtiyaç vardır. Pencereden bakma motifi masaldaki olaylarla ilişskili okunduğunda daha tutarlı bir cevap bulunabilir. İnsan gözü, insan ruhunun dış dünyaya açıldığı bir penceredir. Dolayısıyla pencere insanın iç dünyasının dış dünyaya bir yansımasıdır. Masalda pencere motifi, küçük bir pencereden bakarak komşu bahçesindeki kuzukulaklarına tamah etme ve sonrasında o kuzukulaklarını bahçeden çalmayı ifade eder. Aslında insanın başka kişilerin sahip olduğu şeylere göz dikmesi, bunun sonucunda sahip olma hırsını ve hırsızlık yapma gerçeğini anlatır. Ya da insan davranışının olaylara ve durumlara verdiği tepkileri anlatır. Başkasının sahip olduğu şeye göz dikme sonucunda insan hırs yapar ve bunun sonucunda, sonuca odaklandığı için çalma çözümünü üretebilir. Toplamda ise masalda bir bakışın dahi hareketi başlatma durumu ve gücü anlatılır. Bir bakışla başkasının malına tamah etme davranışı, çocuklarının kendilerinden alınması ile sonuçlanır. Bununla masal, hayatta her davranışın bir reaksiyonu olduğunu anlatır. Böylece hayatta her şey bedel ve karşılığı üzerine kuruludur, yasasını masala verdiği her detay olay ile kanıtlar. Kuzukulağına göz dikme, onu çalma ve buna karşılık olarak anne ve babanın kız çocuklarının ellerinden alınması da bu yasayı ispatlar. Ama insana bir kuzukulağına karşılık çocuğunun elinden alınması pek mantıklı gelmez. Burada da başka detay bir yasa ile karşılaşılır. O da "Hayatta ertelediğin her bedel kişiden artı biriyle çıkar" yasasıdır. 


\section{A. Ertelenen her bedel artı biriyle ödenir}

Hamile kadının kocası kuzukulaklarını ikinci kez çalmaya gider. Yani aldığı bedeli ikiye katlar. Çünkü insan olumsuz bir davranış yaptığında bunu büyüterek yapmaya devam eden bir meyle sahiptir. İnsanın ortaya koyduğu meyil ise onun yönüyle ilgilidir. Bu yön, iyi ve kötü ya da siyah ve beyaz kadar nettir. Eğer o bedel ondan çıkmazsa daha büyügünü yapacağının işareti ikinci kez kuzukulaklarını çalmaya teşebbüs etmesidir. Dolayısıyla toplamda masal kahramanının başlattığı negatif davranış daha büyük bir davranışa doğru gidecektir. $\mathrm{Bu}$ da bir hareketin başladıktan sonra kartopu etkisi göstermesidir. Kızlarının ellerinden alınması o bedelin toplamda +2 bedelle onlardan çıkması anlamına gelir. Çünkü masal kahramanı hatada 1srar eder ve hata ssrarı hayatta ödenecek bedeli büyütmek anlamına gelir. Dolayısıyla erginlenme ya da olgunlaşma şeklinde bir açıklama tek bir noktaya bakıldığında doğru ama toplamdaki olaylarla ilişkilendirildiğinde tutarsız kalabiliyor. Çünkü erginlenme olumlulukta bir olgunlaşmayı ifade eder. Rapunzel 12 yaşına kadar cadıyla beraberdir, 12 yaşından sonra cadı tarafından bir kuleye kapatılır. Tam da erginlenme yaşı olan 12 yaşına kadar cadının yetki ve sorumluluğunda olan Rapunzel, çocukluk dönemini cadının yanında geçirir. İnsan erginlenme sürecinden sonra hayatının kendi yetki ve sorumluluğunu almaya başlar. 12 yaşından sonra kendi hayatının yetki ve sorumluluğunu aldığı göz önünde bulundurularak hata yapmasını engellemek için korumak amacıyla kuleye kapatılır. Bu durum cadının şu sözlerinden anlaşılır: "Ben de sanıyordum ki bütün dünyadan koparıp aldım seni, demek aldanmışım." Prensle birlikte olmaya kendi karar verir. Çünkü hayatının yetki ve sorumluluğunu almıştır. İnsanın sınavı ergenlik döneminde başladığı için kendi hayatında yaptığı hatanın bedelini de Rapunzel öder. Evlilik dışı bir ilişki yaşar ve çocukları olur. Ceza olarak da sürgün edilir. Bir süre açlıkla ve yoklukla sınanır. Yaptığı hatanın bedelini ödedikten sonra prensle tekrar bir araya gelir. Çünkü hayat bedel ve karşıllı̆̆ üzerine kuruludur.

Mahbub-1 Dilber masalında ise pencere kenarında otururken kuşun ona "kız senin bahtın kara." demesi üzerine Mahbub-1 Dilber ve ailesi aslında bulundukları yerden göç etmekle kızlarının ödeyeceği bedelden kaçmak isterler. Pencere yine insanın iç dünyasının hayata bakış tarzının bir işaretidir. Mahbub-1 Dilber ödeyeceği bedeli aslında gözünde büyütür. Ama şu bir gerçek ki herkes hayatta bir şeylerin bedelini mutlaka öder ve sınanır. Annesi ve babası Mahbub-1 Dilber'i sarayda bırakmak zorunda kalırlar. Çünkü bir başkasının bedelini diğerleri ödeyemez. İnsanın hayatta tek başına geçmesi gerekecek yerler vardır. Çünkü hayat insanı tek başına sınamak ister. Anne ve babası onu ne kadar korursa korusun insan kendi gerçeğinden kaçamaz. Bu nedenle anne ve baba kızlarını ödeyeceği bedelden kaçıramaz. Saraya giremeyeceklerini kabullenerek geri dönerler. Mahbub-1 Dilber de sarayda mahsur kalır. Bir yiğidin başında bekleyip sinek kovalayarak bedel öder. Ama son gün pencereden bakarak gördüğ̈ kalburcu kızının kabağı kırma karşısında ailesinden alacağı tepki, bedelini ödemesine engel olur. Burada pencere yine Mahbub-1 Dilber'in iç dünyasının dış dünyaya yansıdığı bir motiftir. Son anda prensi bekleme işini çingene kızına devreder. Kendi bedelini pencereden saçlarına tutunarak çıkan kalburcu kızına ödettiği için sınavını büyütür. Küldöken ismini alır. Prensin başında bekleme bedelinin büyük kısmını kendi ödediği halde son iki hata ile padişahın oğlu ile evlenme ödülünü kaçırır. Bu nedenle bir süre daha sarayda sabrederek sinanır. Sabır duygusal olarak dayanıklılıktır. Ama Mahbub-1 Dilber duygusal olarak dayanıklı bir masal kahramanı değildir. Kuşun söylediğinden sonra evden uzaklaşır, bedelinden kaçar, sarayda mahsur kaldıkça duygusal dayanıklılığı artmaya başlar ama hep son anda hataya düşer. Kalburcu kızlarından ikisinin sudaki Mahbub-1 Dilber'in yansımasının kendileri olduğunu sanarak kırmasına dayanabilir ama üçüncünün kırmasına müdahale eder. Prensin başında 40 gün bekler ama 40. gün bedelini kalburcu kızına ödetir. İnsanın bedel ödeyebilmesi ve önüne gelen sınavı geçebilesi için sabrının artması gerekir. Çünkü aynı zamanda bedel ödemek insanın sabrını da artırır. Fakat Mahbub-1 Dilber sabır bıçağını kendine saplayacağı anda padişahın oğlu tarafindan kurtarılır. Burada masal kahramanının sabretmeden ve bedel ödemeden kaçma meyli vardır. Fakat prensin başında beklediği kırk gün süre ve haksızlığa uğrama bedellerini ödediği için prens 
tarafindan da kurtarılmayı son anda hak eder. Çünkü haksızlığa uğrama anlatı kahramanlarını ve gerçek yaşamda insanı temizleyen güçlendiren bir durumdur. Bunun mesajı insanlığa anlatılar aracılı̆̆ıyla ulaşır. Anlatılarda haksızlığa uğrayan her kahraman Yunus Peygamber kıssası'nda ya da Dede Korkut Hikâyeleri'nde olduğu gibi Dirse Han, Bamsı Beyrek kahramanlarının uğradıkları haksızlıktan sonra ödedikleri bedelin karşılığını mutlaka alırlar.

\section{Başlangıç formelleri}

Başlangıç formelleri ile ilgili tablo şöyledir:

Tablo 1: Başlangıç formelleri.

\begin{tabular}{|l|l|}
\hline \multicolumn{1}{|c|}{ Rapunzel } & \multicolumn{1}{|c|}{ Mahbub-ı Dilber } \\
\hline Başlangıç Formeli: Bir varmış bir yokmuş. & Başlangıç Formeli: Bir varmış bir yokmuş Allah’ın kulu \\
Evvel zaman içinde kalbur saman içinde bir & çokmuş. Evvel zaman içinde kalbur saman içinde bir karı \\
kadın bir de kocası varmış. & kocanın Mahbub-1 Dilber isminde bir kızları varmış. \\
\hline
\end{tabular}

Masallar anlatıcının zaman algısını ve gerçeklik algısını yönlendiren başlangıç formelleri ile başlarlar. $\mathrm{Bu}$ formeller genelde anlatı ile ilgisi olmayan dinleyiciyi buna hazırlayan parçalar olarak masal incelemelerinde yorumlanmıştır. Fakat masallarda başlangıç formelleri dinleyiciyi gerçekliğe hazırlar. Zaman algısı yazılı kültürdeki gibi kronolojik değildir. Sözlü kültür insanı için var olmak ve yok olmak birbiri içine geçmiş, eş zamanlı olarak yaşanan bir olgudur. Dolayısıyla konu gerçeklik olunca sözlü kültür insanının zaman algısının tüm zamanlar için aynı olduğu görülebilir. Çünkü gerçek hiçbir zaman değişmez ve tüm zamanlarda aynıdır. Bu nedenle masallarda imkânsız diye bir şey yoktur. Çünkü zaman, gerçekten yanadır. Anlatılarda ve gerçek hayatta da zaman olaylara bağlı olarak yavaşlar ya da hızlanır. Olaylar hızlandığında zaman da hızlanır, yavaşladığında ise zaman da yavaşlar. Bu nedenle masallarda var olmak ve yok olmak arasında bir zaman farkı yoktur.

\section{Bitiş formelleri}

Bitiş formelleri ile ilgili tablo şöyledir:

Tablo 2: Bitiş formelleri.

\begin{tabular}{|l|l|}
\hline \multicolumn{1}{|c|}{ Rapunzel } & \multicolumn{1}{|c|}{ Mahbub-ı Dilber } \\
\hline Bitiş Formeli: Onları karşılarında görenler düğün & Bitiş Formeli: Kırk gün kırk gece düğün yapılmış, \\
bayram yapmış hep. Prensle Rapunzel ölünceye kadar & $\begin{array}{l}\text { Padişahın oğlu ile Küldöken evlenmiş. Yemiş } \\
\text { mutluluk ve esenlik içinde bir yastığa baş koymuşlar. } \\
\text { içmiş murazlarına / muradlarına ermişler. Onlar } \\
\text { Onlar ermiş muradına, biz çkalım kerevetine. }\end{array}$ \\
\hline
\end{tabular}

Masalların bitiş formellerinde masal kahramanlarından iyi olanların hak ettiği sona kavuştuğu anlatılır. İyi dilek ve duada bulunulur. Bütün masallarda iyi ile kötünün mücadelesi anlatılır ve masalların sonunda iyiler kazanır. İyinin ölçütü ise masalda kendisine bir yasak bildirilen kahramanın bildirilen yasağa uyması, hataya düşen veya yasağı çiğneyen kahramanın olgunlaşması için başına gelen türlü sıkıntılara hakkıyla sabredip doğru tepkileri vermesidir. Başına gelen olaylara nötr tepkiler veren yani problemi kabullenen ve kendisinden istenen çözümü yerine getiren kahraman her zaman kazanır.

\section{Manzum parçalar}

Manzum parçalar ile ilgili tablo şöyledir:

Tablo 3: Manzum parçalar.

\begin{tabular}{|l|l|}
\hline \multicolumn{1}{|c|}{ Rapunzel } & \multicolumn{1}{|c|}{ Mahbub-1 Dilber } \\
\hline "Rapunzel, Rapunzel, sarkıt saçlarını & \begin{tabular}{l}
\multicolumn{1}{|c|}{ "Ay, ben böyle güzel olayım da annem beni kabakla suya } \\
gëndersin.” \\
"Keldim, tutunup çıkayım yukarı! “
\end{tabular} \\
\hline
\end{tabular}

\section{Turkish Studies - Language and Literature}

Volume 14 Issue 4, 2019 
Her iki masalda da tekrar eden manzum parçalar bulunur. Rapunzel masalındaki, iki mısradan oluşan kafiyeli bir yapıdır. Rapunzel ile diyalog kurma işlevi vardır. Prens cadının kuleye çıkarken söylediği kalıp sözleri öğrenerek Rapunzel'e ulaşır. Mahbub-1 Dilber masalının manzum ilk parçası kuşun söylediği "kız senin bahtın kara" kalıp ifadesidir. Bir diğeri ise kalburcu kızlarının kendi kendisiyle konuşması yani monologdan ibarettir. Kalburcu kızı bu manzum parçayı söyledikten sonra Mahbub-1 Dilber' in saçına tutunarak saraya çıkar. Görüldüğü üzere her iki masaldaki bu manzum parçalar masalın epizotlarına ayrılma işlevini üstlenir. Rapunzel iki epizota bölünürken Mahbub-1 Dilber üç epizota bölünür. Ama toplamda her iki masal da üç epizottan oluşur. Sadece Rapunzel'de aileden ayrılma gerçekleşmeden önce kullanılan herhangi bir manzum parça bulunmamaktadır. Bunlar her iki masalda şöyle sıralanabilir:

\section{Masalın manzum parçalarına bağlı oluşan epizotlar}

Masalın manzum parçalarına bağlı oluşan epizotlar ile ilgili tablo şöyledir:

Tablo 4: Masalın manzum parçalarına bağlı oluşan epizotlar.

\begin{tabular}{|c|c|}
\hline Rapunzel & Mahbub-ı Dilber \\
\hline $\begin{array}{l}\text { 1. Ayrılık epizotu } \\
\text { 2. Aileden ARapunzel'in annesinden ve babasından } \\
\text { alınarak cadı tarafindan kuleye hapsedilmesi: Esaret } \\
\text { Bölümü } \\
\text { 3. Rapunzel'in prensle tanıştıktan sonra esaretten kurtulması } \\
\text { ve prensle evlenmesi: Esaretten Kurtulma Bölümü }\end{array}$ & $\begin{array}{l}\text { 1. Ayrılık epizotu } \\
\text { 2. Mahbub-1 Dilber'in sarayda mahsur } \\
\text { kalması: Esaret Bölümü } \\
\text { 3. Mahbub-1 Dilber'in hapsolduğu sarayda } \\
\text { özgürlüğüne kavuşması ve prensle } \\
\text { evlenmesi: Esaretten Kurtulma }\end{array}$ \\
\hline
\end{tabular}

Her iki masalda geçmiş zaman hâkimdir. Masallarda olaylar arası geçişlerde zamanı hızlandıran kalıp ifadeler kullanılmıştır. Bunun dışında "bir süre, sonunda, birkaç yıl, akşam alacakaranlığı" gibi sözlü kültürün zaman algısını yansıtan ve dilde kalıplaşmış ifadeler kullanılmıştır. Her iki masalın zaman ile ilgili bilgileri aşağıdaki tabloda yer almaktadır.

\section{Zaman}

Zaman ile ilgili tablo şöyledir:

Tablo 5: Zaman.

\begin{tabular}{|c|c|}
\hline Rapunzel & Mahbub-ı Dilber \\
\hline Gel zaman, git zaman & Gel zaman git zaman bu kıza bir kuş tebelleş \\
\hline Günlerden bir gün & \\
\hline Zamanla elden ayaktan düşmüş & $\mathrm{Bu}$ kuş her sabah kızın penceresine gelip: \\
\hline Akşam alacakaranlığı & “kız senin bahtın kara!” diyormuş. \\
\hline $\begin{array}{l}\text { Günler geçmiş vakti saati dolunca karısı dünyaya bir kız } \\
\text { çocuğu getirmiş. }\end{array}$ & $\begin{array}{l}\text { Kız derdini bir süre gizlemişse de sonunda } \\
\text { açıklamış. }\end{array}$ \\
\hline $\begin{array}{l}\text { On iki yaşına gelir gelmez büyücü kadın kuleye kapatmış onu. } \\
\text { Ertesi gün akşam olur olmaz }\end{array}$ & $\begin{array}{l}\text { Az gitmişler uz gitmişler dere tepe düz } \\
\text { gitmişler. }\end{array}$ \\
\hline $\begin{array}{l}\text { Ardan birkaç yıl geçmiş, günlerden bir gün kralın oğlu } \\
\text { ormandan geçiyormuş. } \\
\text { Yine bir gün ağacın altına gelip dikilmis }\end{array}$ & $\begin{array}{l}\text { Günler böyle geçmiş. } \\
\text { Kırk gün kırk gece oturmuş sineğini } \\
\text { kovalamıs. }\end{array}$ \\
\hline $\begin{array}{l}\text { Birkaç yıl böyle perişan ve sefil dolaştıktan sonra, sevgilisinin } \\
\text { yaşadığı o kuş uçmaz kervan geçmez yere düşmüş yolu. }\end{array}$ & $\begin{array}{l}\text { Aradan günler aylar geçmiş. Bir gün } \\
\text { padişahın oğlu uzak bir yere gidecekmiş. } \\
\text { Kırk gün kırk gece düğün vapılmıs. }\end{array}$ \\
\hline
\end{tabular}




\section{6. Şahıs kadrosu}

Şahıs kadrosu ile ilgili tablo şöyledir:

Tablo 6: Şahıs kadrosu.

\begin{tabular}{|l|l|}
\hline \multicolumn{1}{|c|}{ Rapunzel } & \multicolumn{1}{c|}{ Mahbub-1 Dilber } \\
\hline Rapunzel & Mahbub-1 Dilber \\
Prens & Kuş \\
Rapunzel'in annesi & Mahbub-1 Dilber'in annesi ve \\
Rapunzel'in babası & Mahbub-1 Dilber'in babası \\
Büyücü & Padişahın oğlu \\
Rapunzel'in ikiz çocukları & Kalburcu kızları \\
& Kalburcu kızı \\
& Sabır taşı ve sabır bıçağını satan adam \\
\hline
\end{tabular}

Rapunzel, masalda açıklandığı şekliyle kuzukulağı anlamındadır. Cadı kuzukulaklarını aşeren annenin doğurduğu bebeğe bu ismi koyarak elinden alır. Mahbub-l Dilber, sevilen dilber anlamına gelmektedir. Küldöken, Mahbub-1 Dilber'in Kalburcu kızın yaptığı hile sonrasında aldığı isimdir.

Türk geleneklerinde eşlerin birbirlerini adları ile çağırma adetleri yoktur. Kadın kocasına "uşşah" şeklinde hitap eder, kocanın gıyabında ise "bizim herif, bizim çocukların babası, "gişim" der. Kocalar ise karılarına "gız" diye hitap ederler, karılarının gıyabında ise "köroğlu, küldöken" gibi terimler kullanırlar (Erdentuğ,70, 1977).

Adıyaman'da günümüzde eşler birbirlerine "bey, hanım, herif”; kadınlar kocalarına "gendi/kendi" terimlerini kullanmaktadırlar.

Kalburcu kızı: Adiyaman'da çingeneler olarak bilinen ve göçebe olarak yaşayan bir topluluk bulunmaktadır. Eskiden kent halkı buğdaylarını elemek için halbur/kalbur veya eleklerini bu çingene dedikleri kişilerden alırlardı. Bu nedenle çingeneler halburcu/kalburcu olarak bilinirler. Adıyaman'da bir çeşit geleneksel mesleğin adıdır. Buradan hareketle Mahbub-1 Dilber'in kendi kültür dairesine özgü bir masal tipi olduğu söylenebilir.

\subsection{Benzerlikler}

Padişahın oğlu- kralın oğlu, Rapunzel'de tek başına büyücü; bir anne ve babanın bir tek kızı Rapunzel'i anne ve babasından ayırma, prens ile Rapunzel'in ayrılığına sebep olma işlevini üstlenirken, Mahbub-1 Dilber'de kuş kızı aileden ayırma kalburcu kızı da padişahın oğlu ile Küldöken'i ayırma işlevini birlikte üstlenir. Her iki masalda anne-baba ve ailenin tek kızı olma motifi var. Anne babanın bir tek kızı var.

\subsection{Farklılıklar}

Rapunzel'de ikiz çocuklar varken Mahbub-1 Dilberde iki kalburcu kızı ve sabır taşı ile sabır bıçağını satan adam şahıs kadrosundaki farklılıklardır.

\section{Mekân}

Her iki masalda mekan iç ve dış mekan olarak verilmektedir. Mekanlar masallarda detaylı bir şekilde betimlenmez. Sadece temayı içeren işlevi olan mekânların önüne epitetler eklenir. Bu duruma "Cadı'nın bahçesi", "ıssız oda", örnek olarak verilebilir. Masalların mekânla ilgili veriler aşağıdaki tabloda yer almaktadır. 
Mekânla ilgili tablo şöyledir:

Tablo 7: Mekân.

\begin{tabular}{|l|l|}
\hline \multicolumn{1}{|c|}{ Rapunzel } & \multicolumn{1}{c|}{ Mahbub-ı Dilber } \\
\hline Rapunzel'in anne ve babasının evi & Mahbub-ı Dilber'in annesiyle ve babasıyla yaşadığı \\
Oturdukları evin arka odası & ev \\
Cadının Bahçesi & Büyük bir dağın başındaki koca kapısı kilitli yüksek \\
Ormandaki tek pencereli kapısız, merdivensiz kule & pencereli saray \\
Kulenin penceresinin altı & Sarayın önündeki pınar \\
Kuş uçmaz kervan geçmez yer & Sarayın penceresinin altı \\
Prensin yaşadığı ülke & Sarayda 1sısız bir oda \\
& Padişahın oğlunun gittiği uzak bir yer \\
\hline
\end{tabular}

Masal motifleri bireysel özelliklerdir, bu motifler diğerleriyle yakın bir ilişkiye girip aynı dizi içinde tekrar tekrar görülürlerse masal formülü olarak daha geniş bir birime yöneltilebilirler (Krohn- Krohn, 2004, 10). Bir masal biriminin motif olabilmesi için bir işlevinin ve onu tanımlayacak bir özelliğinin birlikte verilmesi gerekir. Masal geleneğinde motif devamlılık gösteren masalın en küçük elementidir (Günay, 2011, 20). Bir dantelin ya da oyanın birden çok motifle bütün bir parçayı meydana getirir. İşte masallarda da bir dizi birbiriyle ilişkili olay bir araya gelerek aslında küçük parçaların oluşturduğu bir bütünü, kader motifini oluşturur. Aşağıdaki tabloda her iki masaldaki motifler yer almaktadır: 


\section{Masal motifleri}

Masal motifleri ile ilgili tablo şöyledir:

Tablo 8. Masal motifleri.

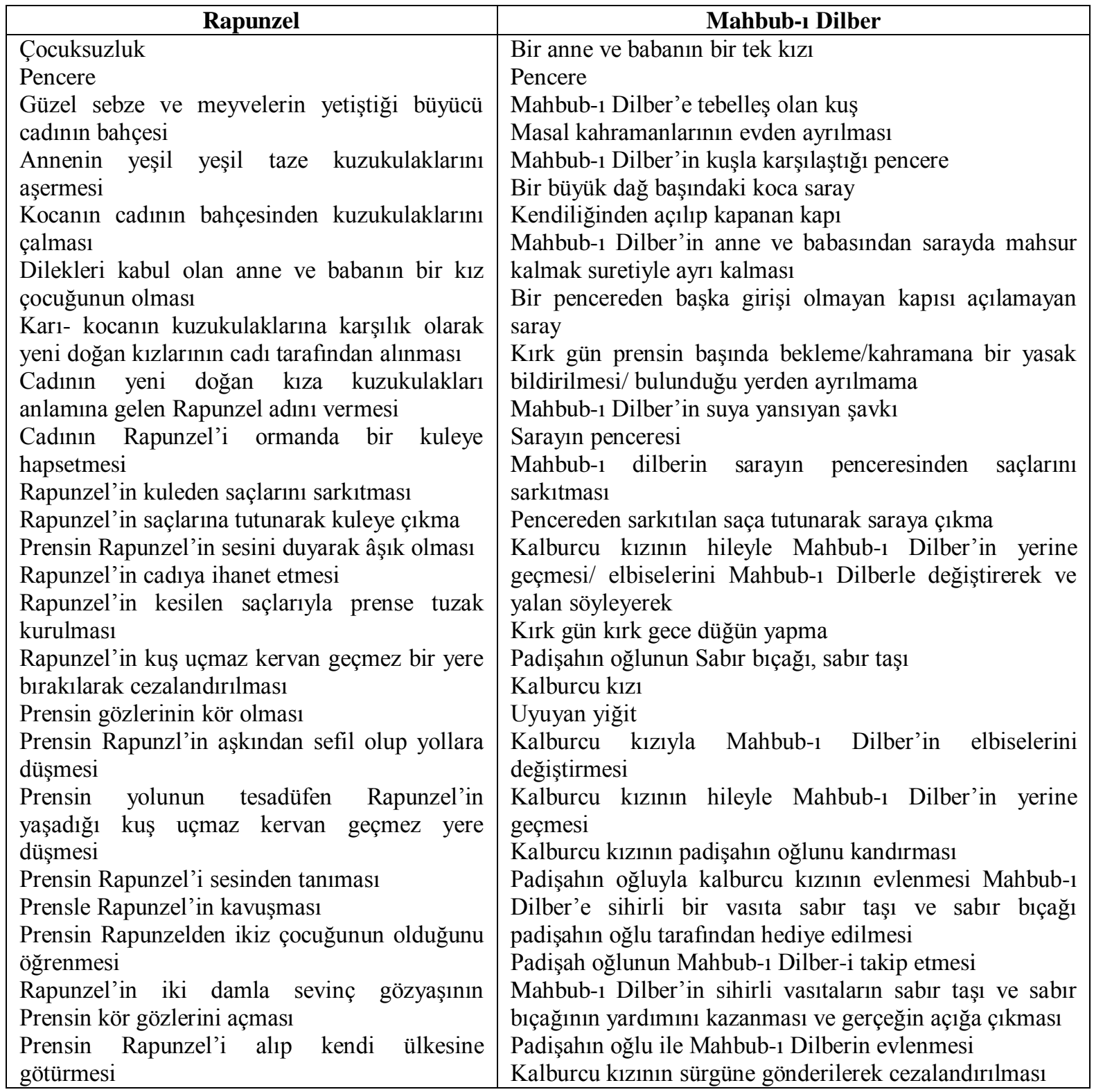

\subsection{Benzerlikler}

Her iki masalda da bir anne ve babanın tek bir kızı vardır. Rapunzel masalında hamile annenin kuzukulaklarını aşerdiği için günden güne sararıp solması ile Mahbub-1 Dilber masalında kahramanın her gün pencereye konan ve kötü haber getiren kuşun söylediklerinden sonra günden güne sararıp solması motifleri benzerlik gösterir. Rapunzel ve Mahbub-1 Dilber masallarında pencereden bakma, pencerenin kenarında oturma motifleri de aynı işleve sahip ortak motiflerdendir. Rapunzel masalında anne hamile kaldıktan sonra evlerinin arka odasındaki küçük pencereden cadının şahane bahçesine bakar. Pencereden bakarak gördüğü kuzukulaklarını aşerer. Rapunzel yüksek kulenin tepesindeki pencereden etrafı izler saçlarını sarkıtır, Mahbub-1 Dilber ise

\section{Turkish Studies - Language and Literature}

Volume 14 Issue 4, 2019 
pencerenin kenarında gergef işler, kuşu görür, sarayın tepsindeki pencereden kalburcu kızlarını izler ve kalburcu kızını pencereden yukarıya çeker.

Rapunzel ve Mahbub-1 dilber evden ayrılmak zorunda kalır. Rapunzel'de büyücü cadının Mahbub-1 Dilber'de ise ayrılığa bir kuşun söyledikleri sebep olur. Her iki masalda da genç kızlık sürecinde/ergenlik Mahbub-1 Dilber yukarıda bir penceresi olan kapısı açılamayan bir sarayda ve Rapunzel tek penceresi olan merdivensiz kapısız bir kulede mahsur kalır. Her iki masalda masal kahramanlarının sarayın veya kulenin iç mekânına tek giriş yeri olan yukarıdaki pencereden sarkıttığı uzun saçlarına tutunarak yukarıya çıkma motifi vardır. Masal kahramanlarının prensin ve kralın oğluyla karşılaşması ve bu kişilere âşık olması da ortak motifler arasındadır. Rapunzel'in kralın oğluyla evlenmesi, Mahbub-1 Dilber'in padişahın oğluyla evlenmesi iki masalın örtüşen motifleridir.

\subsection{Farklılıklar}

Rapunzel masalı çocuksuzluk motifi ile başlar. Ama Mahbub-1 Dilber masalının başında Mahbub-1 Dilber pencerenin kenarında gergef işleyen annesinin babasının biricik kızıdır. Rapunzel masalında çocuksuz anne ve babanın dileklerinin kabul olmasıyla çocukları olur. Ama çocuksuzluğun nasıl çözüme kavuşturulduğu ile ilgili bir detay verilmez. İki masal arasında masal kahramanlarının evden ayrılmalarına neden olan olaylar ve kişiler de birbirinden farklıdır. Rapunzel masalında hamile kadın, komşunun bahçesindeki kuzukulaklarına aşerer. Kocasının büyücü kadının bahçesinden kuzukulaklarını çalması sonucu büyücü, doğacak çocuklarını kendisine vermelerini kocaya teklif eder. Daha sonrasında çocukları doğar doğmaz büyücü gelir ve kızlarını alarak Rapunzel adını koyar. Rapunzel'i alıp evine götürür. Mahbub-1 Dilber masalında bir kuşun her gün Mahbub-1 Dilber'in gergef işlediği pencerenin kenarına konan kuşun "Kız senin bahtın kara." Demesi sonucu göç etmeye karar vermeleriyle evden ayrilma gerçekleşir. Rapunzel masalında düğün motifi yoktur. Ama Mahbub-1 Dilber masalında iki tane kırk gün kırk gece düğün motifi vardır. Kralın oğlu kuleye ilk çıktığında Rapunzel'e evlenme teklif eder ama sonrasında herhangi bir düğün yapılmaz. Cadının, prensin kuleye geldiğini öğrenmesinden sonra Rapunzel'in kuş uçmaz kervan geçmez bir yerde prensten ikiz çocuk sahibi olduğundan bahsedilir. Rapunzel masalında evlenmeden çocuk sahibi olma motifiyle karşılaşıyoruz. Masalda cadının Rapunzel'i cezalandırma sebebi, prensle evlilik dişı yasak bir ilişki yaşayarak kendisine ihanet etmesidir. Mahbub-1 Dilber masalında gerçeğin ortaya çıkmasını sağlayan sabır taşı ve sabır bıçağı olmak üzere iki tane sihirli nesne motifi ile karşılaşırız. Ancak Rapunzel'de sihirli bir nesne yer almaz. Olağanüstü motif olarak Rapunzel'e prensin kuş uçmaz kervan geçmez yerde birbirlerine kavuştuklarında Rapunzel'in döktüğü sevinç gözyaşlarından prensin kör olan gözlerinin açılması motifi vardır.

\section{Sonuç}

İki farklı kültüre mensup Mahbub-ı Dilber ile Rapunzel masallarının karşılaştırılması sonucunda her iki masalın benzer ve farklı motiflerinin olduğu tespit edilmiştir. Masallarda benzerlikleri ana motiflerin sağladığı, farklılıkların ise ara motiflerden kaynaklandığı görülür. $\mathrm{Bu}$ kapsamda masal incelemelerinde ana motifin yanında, diğer bir ana motife geçişi doğuran ara motif terimi, bir inceleme yöntemi olarak sunulabilir. Bir oyayı ya da danteli birbirine bağlayan zincirlerden, örümcek ağından oluşan yan motifler diğer ana motifleri birbirine bağlar. Anlatılarda da aynı tekniğin varlığından söz edilebilir. Örneğin Rapunzel ve Mahbub-1 Dilber masallarındaki pencere motifi yeni bir boyuta geçişin ifadesi olarak ana bir motiftir. Ancak bu ana motiften diğer bir ana motife yani evden ayrılmaya sebep olan ara motifler masallar arasındaki farklılığa sebep olan asıl unsurdur. Rapunzel'de bahçesinden kuzukulakları çalınan cadının, Mahbub-1 Dilber'de ise pencereye konan kuşun evden ayrılmaya neden olan ara motiflerdir. Pencere kenarında gergef işleme, dikiş dikme motifi Batı masallarında da karşılaşılan bir motiftir. Bu motif ara motif olarak Mahbub-1 Dilber'de yer alırken Rapunzel'de yer almaz. Rapunzel masalı çocuksuzluk motifi ile

\section{Turkish Studies - Language and Literature}

Volume 14 Issue 4, 2019 
başlar. Çocuksuzluk motifi Türk halk anlatılarından destanlarda ve halk hikâyelerinde daha sıklıkla görülen bir ana motiftir. Bu motif Mahbub'1 Dilber masalında yer almamakla beraber, masal kahramanının evin tek kızı olması aslında onun da çocuksuzluk motifine bağlı dünyaya geldiğini anımsatmaktadır. Her iki masalda, masal kahramanlarının ayrılığı ana motifi yer alır. Fakat ara motif olarak Rapunzel'de kavuşmalarına engel olan kişi büyücüyken diğerinde kalburcu kızıdır. Türk halk anlatılarında dügün motifi ana bir motif olarak yer alır. Mahbub-1 Dilber masalında hileyle kendisiyle evlenen kalburcu kızına ve padişahın oğlunu asıl bekleyen Mahbub-1 Dilber'e de kırk gün kırk gece dügün yapılır. Rapunzel masalında evlilik dışı ikiz çocukların dünyaya gelişi motifi görülmektedir. İkizlerin atmosferdeki düzensizlikle bir ilgileri olduğu, Kanada dâhil dünya çapında yaygın kabul görmüş bir şeydir (Levi-Strauss, 2013, 60). Dolayısıyla Rapunzel'in evlilik dışı olan ikiz çocukları bir yasağın ihlalinin bir işareti olarak okunabilir. Bu yönüyle masallar birbirinden ayrılmaktadır. Çünkü Türk halk anlatılarında âşıkların birbirine kavuşması sonucunda masallar kırk gün kırk gece motifi ile biter. Ama Rapunzel'de prensin onu alıp ülkesine götürmesiyle masal biter. Sadece onları görenlerin düğün bayram ettiğinden söz edilir. Rapunzel'de masalın sonunda kör olan gözlerin açılması motifi Türk halk anlatılarında masal ve halk hikâyelerinde de yer alan bir motiftir. Fakat Türk halk anlatılarında daha çok gözlerinin açılması tedavi ile söz konusu olabilmektedir (Alptekin, 2009) Her iki masalda saçlarını yüksek bir yerden sarkıtma motifi vardır. Mahbub-1 Dilber masalının Adıyaman'a özgü yerel bir masal tipi olduğu görülmüştür. Sonuç olarak her iki masal arasında farklılıklardan çok benzer yönlerin olduğu görülmüştür. Masallar arasındaki kültürel kod farklılığının sebebi her bir masalın coğrafi birer ekotip olmasından kaynaklandığı söylenebilir. Bu durum, masalların aslında kültür endüstrisinde neden daha çok tercih edildiğinin de cevabını içinde taşır. Dünya masalları karşılaştırıldığında kolektif bilinçdışında birçok ortak kodu paylaştığı görülür. Dolayısıyla bir masal bir çizgi animasyona ya da sinema sektöründe bir ürüne dönüştüğünde çok hızlı bir şekilde farklı kültürler arasında yayılabilmektedir. Ancak burada göz önünde bulundurulması gereken en önemli durum bu masallar yayılırken, yayıldıkları ve yerleştikleri toplumun kültürel kodlarını da silme gücüne sahiptir. Bu da beraberinde yayıldıkları kültürlerde genetik kodlarda anomalik bir duruma sebebiyet verir. Çünkü masalların bireyin kültürel kodlarını programlama gücü yadsınamaz bir gerçektir. Yerleştiği toplumun yaşantısını dönüştürme gücü nedeniyle, bireyin içinde yaşadığı topluma uyumunu da etkiler. Bu durum, kültürlerin deformasyonuna yol açarken bir toplumun kendi anlatılarını unutmasına ve kendi kültürüne yabancılaşmasına da temel teşkil eder. Böylece daha güçlü küresele yayılan kültür endüstrisi ürünleri karşısında yerel anlatılar silinip gider. Karşılaştırmalı masal çalışmaları, Anadolu masallarını kültür endüstrisi alanında ürüne dönüştürülebilmesi için yeniden hatırlanması konusunda bilinç oluşturabilir. Yerel masal tiplerinin karşılaştırmalı olarak çalışılması kültür endüstrisi alanına Türk masallarının kazandırılması kapsamında bir katkı sağlayabilir.

\section{KAYNAKÇA}

Alptekin, A. B. (2009). Türk Masal ve Halk Hikâyelerinde Görmeyen Gözün Tedavi Edilmesi Motifi Üzerine. Milli Folklor, 81, 18-26.

Azadovski, M. (2002). Sibirya'dan Bir Masal Anası. Çeviren: İlhan Başgöz, Ankara, T. C. Kültür Bakanlığı Yay.

Dundes, A. (2007). Antropolog ve Folklorda Karşılaştırmalı Metot. Milli Folklor Çeviren: Ferya Çalış, 73, 81-95.

Eberhard, W. - Boratav, P. N. (1953). Typen Turkischer Volkmärchen. Franz Steiner Verlag GMBH, Wiesbaden 
Erdentuğ, A. (1977).Türkiye, İran ve Pakistanda Geleneksel Köy Ailesinin Özellikleri. Ankara Üniv. Dil Coğrafya ve Tarih Fakültesi Antropoloji Dergisi, 10, 63-74.

Ergun, P. (2014).Türk Masal Anlatıcısının Kimliği. Milli Folklor, 104, 33-45.

Fromm, E. (2003). Rüyalar, Masallar, Mitoslar. Çeviren: Aydın Arıtan, ve Kaan H. Ökten, İstanbul, Arıtan Yay.

Grimm, J.\&Grimm W. (2018). Grimm MasallarıI-II. Çeviren: Kamuran Şipal,, İstanbul, YKY.

Günay, U. (2011) .Elazı̆̆ Masalları ve Propp Metodu, Ankara, Akçă̆ Yay.

Krohn, \&Krohn, K. (1996). Halk Bilimi Yöntemi. Çeviren: Günseli İçöz, Ankara TDK Yay.

Levi-Strauss, C. (2013). Mit ve Anlam. Çeviren: Demir Gökhan Yavuz, İstanbul, İthaki Yay.

Von Sydow, C. W. (2005). Coğrafya ve Masal Ekotipleri, Halkbiliminde Kuramlar ve Yaklaşımlar 2, Çeviren: Tuğçe Işıkhan, Yayına Hazırlayanlar: Öcal Oğuz, Selcan Gürçayır, Ankara, Geleneksel Yayıncilik.

\section{Ekler:}

\section{Masalların Özeti:}

\section{Mahbub-ı Dilber}

1. Bir karı ile kocanın Mahbub-1 Dilber adında bir kızları varmış.

Gel zaman git zaman

2. Bir kuş bu kıza musallat olur.

3. Kuş her sabah gelip kız pencere kenarında gergef işlerken pencerenin kenarına konar "Kız senin bahtın kara." Der.

4. Kız, derdinden günden güne sararıp sormaya başlar. Annesi ile babası bir kuşun söylediklerinin kızlarını üzdüğünü, kızlarına sorarak öğrenirler.

5. Kızın annesi ile babası çareyi oradan göçmekte bulur. Anne ile baba kızlarını yanlarına alarak yola koyulurlar.

Az gitmiş̧ler, uz gitmiş̧ler, dere tepe düz gitmişler.

6. Bir büyük dağın başında koca bir saray görürler. Sarayın büyük bir kapısı vardır. Kapıyı babası zorlar açılmaz. Annesi kapıyı zorlar açılmaz. Mahbub-1 Dilber kapıyı zorlayınca kapı kendiliğinden açılır.

7. Kız içeri girince kapı birdenbire kapanır. Kız içerde annesi ve babası dışarıda kalır.

8. Kızın annesi ve babası kızlarından sarayda ne olduğunu bakıp kendilerine söylemesini ister. Saray bomboştur. Kız, sarayda sadece civan gibi bir delikanlı yiğidin bir köşede uyuduğunu görür. Annesine ve babasına kapının arkasından durumu açıklar.

9. Babası ve annesi kızlarının kaderinin böyle olduğunu ve yiğidin başında beklemesini söylerek oradan ayrılırlar.

10. Kız oğlanın başında kırk gün kırk gece oturur. Oğlanın başına konan sinekleri kovalar. Oğlan uyanmaz.

11. Kırkıncı günde dışardan sesler duyar. Pencereden baktığında üç kalburcu kızının sarayın önündeki pınardan su aldıklarını görür. Kız pencerenin kenarına oturunca şavkı suya düşer. Kalburcu kızları bu şavk kendilerinin sanarak ellerindeki su kabaklarını kırarlar. Ama üçüncüsünün su kabağını kırmasına Mahbub-1 dilber pencereden seslenerek engel olur. 
12. Kalburcu kızı Mahbub-1 Dilber-i pencerede oturuyor görünce onun yanına çıkmak için istekte bulunur. Kalburcu kızı Mahbub-1 dilberden saçını uzatmasını ister. Kalburcu kızı saçına tutunarak saraya çıkar. Mahbub-1 dilber başından geçenleri kalburcu kızına anlatır. Yiğidi kalburcu kızına gösterir.

13. Kalburcu kızı Mahbub-1 dilberin yerine geçmek için onunla elbiselerini değiştirir. Mahbub-1 dilberin yerine geçerek onun dinlenmesi için pencerenin kenarına oturtur. Kendisi de Yiğidin başına oturur. Sinekleri kovalar. Bir süre sonra Yiğit uyanır.

14. Yiğit uyandığında kalburcu kızını başında beklerken görür. Kim olduğunu sorar. Kalburcu kızı da 40 gündür onun başında bekleyerek sineklerini kovaladığını anlatır. Mahbub-1 Dilber'i de Küldökeni olarak tanıtır.

15. Uyuyan yiğit padişah oğludur. Padişahın oğlu ile kalburcu kızı 40 gün 40 gece bir düğün ile evlenirler.

16. Aradan günler, aylar geçer. Padişahın oğlu uzak bir yere gider. Gitmeden önce kalburcu kızına ve küldökene hediye olarak ne istediklerini sorar. Kalburcu kızı güzel elbiseler 1smarlar. Küldöken de bir sabır taşı ile sabır bıçağı ister. Küldöken eğer istediklerini getirmezse önün arkan sur olsun diye beddua eder.

17. Padişahın oğlu Kalburcu kızının isteklerini alır ama Küldöken'in hediyelerini unutur. Bu nedenle Küldöken'in bedduası gerçekleşir. Önü arkası sur olur. Hemen dönüp sabır taşı ve sabır bıçağını satın alır. Sabır taşı ve sabır bıçağını satan adam padişahın oğlunu bu hediyeyi vereceği kişiyi iyi takip etmesi ve dikkatli olması konusunda uyarır.

18. Padişahın oğlu saraya döner ve hediyeleri verir.

19. Ertesi gün Kalburcu kızı Küldöken ile hamama gitmek ister.

20. Küldöken yolda tarağı unuttuğunu hatırlayıp saraya geri döner.

21. Sabır taşı ve sabır bıçağını alıp ıssız bir odaya çekilir.

22. Sabır taşı ile konuşmaya başlar. Başından geçen her şeyi sabır taşına anlatır.

23. Padişahın oğlu gizlice Küldökeni dinler. Küldöken tam bıçağı saplayacağı esnada Padişahın oğlu yetişip bıçağı elinden alır.

24. Kalburcu kızını hamamdan getirir ve saraydan kovar.

25. Kırk gün kırk gece düğün yapılmış Padişahın oğlu ile Küldöken evlenirler.

\section{Rapunzel}

1. Uzun zamandan beri çocuk sahibi olmayan bir karı ve koca vardır.

2. Tanrı'dan çocuk dilerler ve dilekleri gerçekleşir ve kadın hamile kalır.

3. Oturdukları araka odanın küçük bir penceresi vardır. O pencere yüksek duvarlarla örülü ve birbirinden güzel sebze ve meyvelerin yetiştiği bahçesi olan bir eve bakar. Bu ev azılı bir büyücüye aittir.

4. Kadın odadaki pencereden bahçeyi izlerken bahçedeki kuzukulaklarını canı çeker. Ama kuzukulaklarını almaya cesaret edemezler. Bu nedenle Gün geçtikçe hamile kadın elden ayaktan düşer, sararıp solar ve zayıflar, kötüleşip acınacak duruma gelir.

5. Kocası karısinın bu durumunu fark eder ve karısına derdini sorar. $\mathrm{O}$ da kuzukulaklarını yemezse öleceğini söyler.

6. Kocası her şeyi göze alıp bahçeye girmeye karar verir. 
7. Bahçeye akşam girer ve kuzukulaklarını alır. Karısı da hemen salata yapıp yer. Ertesi gün kuzukulakları hamile kadının daha çok burnunda tütmeye başlar. Adam karısı üzülmesin diye bahçeye yine girer. Büyücü onu yakalar. Adam da hamile karısı için kuzukulaklarını bahçeden aldığını söyler. Cadı doğacak çocuklarını kendisine getirmek şartıyla kuzukulaklarından diledikleri kadar alabileceklerini söyler. Adam korkusundan büyücünün her dediğini kabul eder.

8. Günler geçip vakti saati dolunca hamile kadın bir kız çocuğu dünyaya getirir. Büyücü kadın yetişip kız çocuğuna Rapunzel adını koyarak ellerinden alır.

9. Rapunzel kadar güzel bir çocuk dünyada yoktur. Rapunzel iki yaşına girince büyücü kadın onu ormanın içinde kapısı ve merdiveni olmayan ancak çok yüksekte tepede bir tek penceresi olan bir kuleye kapatır.

10. Büyücü kadın kuleyi çıkmak istediğinde Rapunzel'den sırma saçlarını sarkıtmasını ister ve saçlarına tırmanarak kuleye çıkar.

11. Aradan birkaç y1l geçer. Kralın oğlu ormanda gezinirken tam kulenin yanına geldiğinde birinin şarkı söylediğini işitir. Prens Rapunzel'in sesini çok beğenir. Kuleye çıkmak ister. Fakat kulenin baktığında hiçbir kapı olmadığını görür. Atına atlayıp saraya döner. Ama duyduğu güzel sesi unutamaz. Her gün ormana gidip Rapunzel'in söylediği şarkıları dinlemeden yapamaz.

12. Bir gün prens Rapunzel'in söylediği şarkıları dinlemek için geldiğinde orada büyücü kadının Rapunzel'in saçlarına tırmanarak kuleye çıktığını görür.

13. Ertesi gün sular kararmaya başladığında kuleye gelir ve büyücü kadının söylediği gibi Rapunzel'e seslenir ve Rapunzel'in saçlarına tırmanarak kuleye çıkar.

14. Prens Rapunzel'e evlenme teklif eder.

15. Rapunzel kuleden kçamak için prensten her kuleye gelişinde kendisine ip getirmesini ister. Bu iple merdiven örüp kuleden kaçabileceğini düşünür. Bu olanlardan büyücü kadının haberi olmaz.

16. Rapunzel bir gün prensin kuleye geldiğini ağzından kaçırır. Büyücü kadın sinirlenir. Rapunzel'in saçlarını keser.

17. Rapunzel'i kuş uçmaz, kervan geçmez bir yere bırakarak cezalandırır.

18. Kuleye gidip Rapunzel'in kestiği saçlarını bir çengele geçirerek aşağı sarkıtır. Prens kuleye çıktığında büyücü kadın ile karşılaşır. Büyücü kadın prense bir daha Rapunzel'i göremeyeceğini söyler.

19. Prens üzüntüsünden kendini kuleden aşağı atar. Ölmez ama gözüne batan dikenler onu kör eder. geçmez yere düşer.

20. Prens birkaç yıl aç sefil dolaşır. Yolu sevgilisinin yaşadığı kul uçmaz kervan

21. Bu arada Rapunzel'in ikiz çocuğu olur. Ah vah ederek günlerini geçirir.

22. Prens uzaktan Rapunzel'in sesini duyar. Yaklaşınca Rapunzel onu tanır ve prensin boynuna sarılarak ağlamaya başlar. İki damla gözyaşı da prensin gözlerine akar. Prensin görmez gözü görür olur.

23. Rapunzel'i alıp kendi ülkesine götürür.

24. Onları karşılarında görenler düğün bayram yapar.

25. Ölünceye kadar esenlik ve mutluluk içinde bir yastığa baş koyarlar (Grimm \&Grimm, 2018).

\section{Turkish Studies - Language and Literature}

Volume 14 Issue 4, 2019 